\title{
Extinction of the overshadowing CS after overshadowing in conditioned taste aversion
}

\author{
TODD R. SCHACHTMAN \\ University of Missouri, Columbia, Missouri \\ WESLEY J. KASPROW and ROBERT C. MEYER \\ Northern Illinois University, DeKalb, Illinois \\ and \\ MARK J. BOURNE and JULIE A. HART \\ University of Missouri, Columbia, Missouri
}

\begin{abstract}
Using a conditioned taste aversion preparation, overshadowing of flavor-illness association was produced through the presentation of a second flavor during the interval between the first flavor and illness. The modulatory effects of extinguishing the association between the second (overshadowing) flavor and illness on conditioned responding to the target flavor was investigated. In Experiment 1, we found that, following one-trial overshadowing, extinction of the overshadowing flavor had no effect on conditioned responding to the target flavor. In Experiment 2, we found a similar absence of an effect of extinction of the overshadowing stimulus in a multitrial overshadowing paradigm. Experiment 3 confirmed the results of Experiments 1 and 2 using conditioning parameters that were designed to weaken the association between the overshadowed flavor and illness. In Experiments 4 and 5, we used simultaneous presentation of the flavors during conditioning and obtained a weakened aversion to the overshadowed flavor when the overshadow. ing CS was extinguished. These findings are inconsistent with previous observations in conditioned fear preparations that suggest that extinction of the association between the overshadowing stimulus and the unconditioned stimulus attenuates overshadowing. Possible reasons for the discrepant results are discussed.
\end{abstract}

When a weak conditioned stimulus (CS), such as a soft tone, is presented simultaneously with another more salient CS, such as a bright light, and this stimulus compound is immediately followed by an unconditioned stimulus (US), such as footshock, the conditioned response (CR) to the tone is less than if the light had been absent from the stimulus compound (Kamin, 1969; Pavlov, 1927). Thus, the light, by virtue of its greater salience, appears to reduce the ability of the animal to learn the tone-shock relationship. This phenomenon has been called overshadowing. Overshadowing has also been observed when one element of a sequential compound stimulus is more proximal to the unconditioned stimulus; that is, a less contiguous element can be overshadowed by a more contiguous element (e.g., Kaye, Gambini, \& Mackintosh, 1988).

Typically, multiple conditioning trials are used in studies of overshadowing (e.g., Kamin, 1969; Mackintosh, 1976).

We thank B. Butchart, J. Calton, J. Chelonis, K. Gustavson, and M. McEwen for assistance with the experiments and D. Knipp for his help with the preparation of this manuscript. Address correspondence concerning this article to W. J. Kasprow, Department of Psychology, Yale University, Box 11A Yale Station, New Haven, CT 06520-7447, or to T. R. Schachtman, Department of Psychology, University of Missouri, Columbia, MO 65211.
However, single-trial instances of overshadowing have been observed (James \& Wagner, 1980; Kaye et al., 1988; Mackintosh, 1971; Mackintosh \& Reese, 1979). Prevailing theoretical interpretations of overshadowing attribute the reduction in CR seen following these procedures to the failure of association between the overshadowed CS and the US. However, recent research suggests that overshadowing following multiple conditioning trials is not due to an associative deficit; rather, an association between the overshadowed stimulus and the US is learned but is not expressed in behavior. Kasprow, Cacheiro, Balaz, and Miller (1982) used the technique of memory reactivation to restore the $C R$ based on an association between an overshadowed CS and a US using a multitrial conditioning paradigm. Specifically, Kasprow et al. presented the overshadowed stimulus briefly to subjects in a different context before a test of that stimulus in the training context and found a restoration of the CR. A brief CS exposure was used during these "reminder treatments" to prevent appreciable extinction of the overshadowed stimulus from occurring (Gordon, Smith, \& Katz, 1979). It has been hypothesized that such stimulus exposure served to reactivate the association between the overshadowed stimulus and the US and caused further processing of it, so that retrieval of the association at the time of testing was facilitated (see Spear, 1978). 
A second line of evidence supports the conclusion that multitrial overshadowing is reversible. Kaufman and Bolles (1981), Matzel, Schachtman, and Miller (1985), and Matzel, Shuster, and Miller (1987) showed that postconditioning extinction of the overshadowing stimulus enhances CR to an overshadowed stimulus at the time of testing. These studies used a conditioned suppression procedure. Matzel et al. $(1985,1987)$ interpreted their findings within the framework of the "comparator hypothesis" of Miller and Schachtman (1985; see also Kasprow, Schachtman, \& Miller, 1987; Schachtman, Brown, Gordon, Catterson, \& Miller, 1987). The comparator hypothesis posits that responding to a CS is a function of the relative associative strength of that $\mathrm{CS}$ to the associative strength of other stimuli that are spatially and temporally proximal to the $\mathrm{CS}$ during conditioning (comparator stimuli). A CR depends on the current value of the comparator stimulus at the time the CS is tested; that is, responding is influenced by postconditioning modifications of the comparator stimulus. An overshadowing CS might be expected to serve as the comparator stimulus for an overshadowed CS due to the temporal proximity of these CSs. This view not only predicts multitrial and one-trial overshadowing but also reversal of these deficits through extinction of the overshadowing stimulus. Such extinction is viewed as reducing the value of the comparator stimulus.

The present study served two purposes. First, the experiments were designed to investigate the effectiveness of extinction of the overshadowing CS in attenuating manifest overshadowing following one-trial and multitrial overshadowing. As described above, such extinction has reversed multitrial overshadowing, but extinction has not been shown to exert an effect with one-trial overshadowing.

Second, this study examined the potential for recovery from overshadowing by extinction of the overshadowing stimulus using a conditioned taste aversion (CTA) procedure. The effects of extinction of the overshadowing CS in CTA are unclear. Revusky, Parker, and Coombes (1977) found no effect of extinction of the overshadowing CS following a single compound conditioning trial. Speers, Gillan, and Rescorla (1980), using multitrial conditioning, found that extinction of the overshadowing CS actually reduced, rather than enhanced, the CR to the overshadowed CS. Revusky et al. (1977) used a sequential compound, whereas Speers et al. used a simultaneous compound. Presumably differential extinction effects were seen due to the presence of within-compound associations in the latter study and not in the former. These two overshadowing studies suggest that extinction of the overshadowing CS does not enhance CR to the overshadowed CS. This stands in contrast with previous positive results obtained with a conditioned suppression procedure. At present, it is not known whether the relevant difference is the amount of compound stimulus conditioning or the conditioning preparation. The present research attempted to clarify this issue. A CTA preparation was also used because of the robust single-trial conditioning typically observed in this preparation. Moreover, one-trial over- shadowing has been observed in CTA (e.g., Kaye et al., 1988; Revusky et al., 1977).

\section{EXPERIMENT 1}

Experiment 1 attempted to produce one-trial overshadowing of an association between a target flavor and illness through the presentation of a second flavor that was more proximal to the US than the second flavor. The association between the second flavor and illness was then extinguished for some animals on the premise that such extinction would reduce overshadowing.

\section{Method}

Subjects and Apparatus. Seventy experimentally naive adult male hooded rats from the colony at Northern Illinois University served as subjects. The rats were approximately 110 days old at the start of the study and had a mean free-feeding body weight of approximately $395 \mathrm{~g}$. The subjects were singly housed in wire mesh and sheet metal cages in a room that was maintained on a 16-h light:8-h dark daily cycle. The rats had free access to food. They were acclimated to a 23.5 -h water-deprivation schedule starting 8 days before the start of the study. Water in the home cage was delivered approximately $1 \mathrm{~h}$ following all scheduled experimental treatments, including test days. The subjects were handled for $1 \mathrm{~min}$ per day for 8 days before the start of the study. All experimental treatments took place in the home cage. During the experiment, fluids were delivered in a $50-\mathrm{ml}$ plastic centrifuge tube with a metal drinking spout. Two flavors were used: $1 \%(\mathrm{w} / \mathrm{v})$ saline (Sal) and $5 \%(w / v)$ sucrose (Suc). These flavors were employed because pilot work with overshadowing procedures similar to the present experiments yielded no effect of flavor and no interactions of flavor with treatments. The US was a $1.6 \%$ body-weight i.p. injection of 0.3-M LiCl. Solutions were made with distilled water.

Procedure. For 3 days before the start of the experiment, all animals were allowed to drink distilled water from the drinking tubes for $5 \mathrm{~min}$ to acclimate them to the tubes. The animals were then assigned to treatment conditions, counterbalancing for water intake on the last preliminary day and ad-lib body weight; there were six treatment groups.

On Days 1 and 2, conditioning was conducted with nontarget flavors presented in isolation (Day 1) and target flavors paired with illness (Day 2). For the sake of exposition, the overshadowing flavor is designated as $A$, and the overshadowed flavor is designated as $X$. For half of the subjects, $A$ was $S a l$ and $X$ was Suc; for the other half of the subjects, the roles of the flavors were reversed. On Day 1, Group O (overshadowing) ( $n=12$ ) and Group O-E (overshadowingextinction) $(n=12)$ received distilled water $(W)$ in the drinking tubes for $5 \mathrm{~min}$. Group $\mathrm{OC}$ (overshadowing control) $(n=12)$ and Group OC-E (overshadowing control-extinction) $(n=11)$ received flavor A for $5 \mathrm{~min}$. Groups SC (systemic control) $(n=11)$ and SC-E (systemic control-extinction) $(n=12)$ received flavor $\mathrm{X}$ for $5 \mathrm{~min}$. All animals received $30 \mathrm{~min}$ of tap water in the home cage $1 \mathrm{~h}$ following treatment. On Day 2, Groups $\mathrm{O}$ and $\mathrm{O}-\mathrm{E}$ received $X$ for $5 \mathrm{~min}$. Forty minutes later, they received $A$ for $5 \mathrm{~min}$. $\mathrm{LiCl}$ injection followed the offset of $A$ by $5 \mathrm{~min}$. Groups $O C$ and $O C-E$ received $\mathrm{X}$ for $5 \mathrm{~min}$. Forty minutes later, they received distilled water for 5 min. Five minutes later, they were injected with $\mathrm{LiCl}$. Groups SC and SC-E received distilled water for $5 \mathrm{~min}$, followed $40 \mathrm{~min}$ later by a 5 -min presentation of $A$. They were injected with $\mathrm{LiCl} 5 \mathrm{~min}$ later. All animals received $30 \mathrm{~min}$ of tap water in the home cage $3 \mathrm{~h}$ following the injection.

Extinction of the overshadowing flavor, A, or presentation of water began on Day 3 and continued for 5 days. Once each day, Groups O-E, OC-E, and SC-E received a 5-min exposure to A. 
Groups $\mathrm{O}, \mathrm{OC}$, and $\mathrm{SC}$ received a 5 -min exposure to distilled water All solutions were presented in the experimental drinking tubes.

On Days 8 and 9 , conditioned aversion to $X$ was tested. All animals received a 5 -min single-tube test.

\section{Results and Discussion}

Average intake of the nontarget solution (i.e., the solution presented unpaired with illness) ranged from 11.0 to $12.8 \mathrm{ml}$ across the groups on Day 1 . The groups did not differ on these values $[F(5,64)=1.52, p>.10]$. Intake for the first solution presented on the conditioning trial (W for Groups SC and SC-E; X for Groups OC, $\mathrm{OC}-\mathrm{E}, \mathrm{O}$, and $\mathrm{O}-\mathrm{E}$ ) ranged from 10.6 to $12.6 \mathrm{ml}$. There was an effect of treatment on these values $[F(5,64)=$ $2.58, p<.05$ ]. Between-group comparisons showed that Groups SC and SC-E's intake of W was lower than Group $\mathrm{O}$ and $\mathrm{O}-\mathrm{E}$ 's intake of $\mathrm{X}(p s<.05)$. Intake of the second solution on the conditioning trial (W for Groups OC and OC-E; A for Groups SC, SC-E, O, and O-E) ranged from 7.9 to $10.1 \mathrm{ml}$. There was an effect of treatment on this measure $[F(5,64)=2.47, p<.05]$. Additional between-group comparisons showed that Groups $O C$ and OC-E drank less W than Groups $O$ and O-E drank $A(p s<.05)$. Thus, differences on the conditioning trial consistently reflected a greater intake of saline or sucrose relative to water.

On the first flavor A extinction trial, Group SC-E drank $1.5 \mathrm{ml}( \pm 0.7)$, Group OC-E drank $9.4 \mathrm{ml}( \pm 0.5)$, and Group O-E drank $1.7 \mathrm{ml}( \pm 0.5)$ (all values = group means $\pm S E M s)$. This reflects the formation of a strong aversion to flavor A in Groups SC and O. Group OC-E did not form an aversion to flavor A because that flavor was presented unpaired with illness for this group. This low intake by Group SC-E (which received A-LiCl trials), relative to the large amount consumed by Group OC-E (which received $\mathrm{X}-\mathrm{LiCl}$ trials) suggests an absence of substantial generalization between $\mathrm{A}$ and $\mathrm{X}$. By the last extinction trial, Group SC-E drank $11.0 \mathrm{ml}( \pm 0.6)$, Group OC-E drank $12.0 \mathrm{ml}( \pm 0.7)$, and Group O-E drank $11.0 \mathrm{ml}( \pm 0.8)$, showing that the aversion in Groups SC-E and O-E extinguished over five extinction trials. This pattern of results was reflected in a treatment (OC-E vs. SC-E vs. O-E) $\times$ trial repeated measures analysis of variance (ANOVA) on the data from these three groups. This ANOVA obtained a main effect of treatment $[F(2,32)=11.33, p<.001]$, a main effect of trial $[F(4,32)=96.74, p<.001]$, and an interaction of these two factors $[F(8,128)=11.12, p<.001]$. Groups SC-E and $\mathrm{O}-\mathrm{E}$ significantly increased their intake of flavor $\mathrm{A}$ over extinction trials $[F \mathrm{~s}(4,44)=62.84$ and 40.45 , respectively, $p s<.001]$. Unexpectedly, Group OC-E also increased intake over the extinction trials $[F(4,40)$ $=6.93, p<.001]$. Presumably, the increase was due to dissipation of neophobia. Nevertheless, these three groups did not differ in their intake of $\mathrm{A}$ on the last extinction exposure $(p>.10)$.

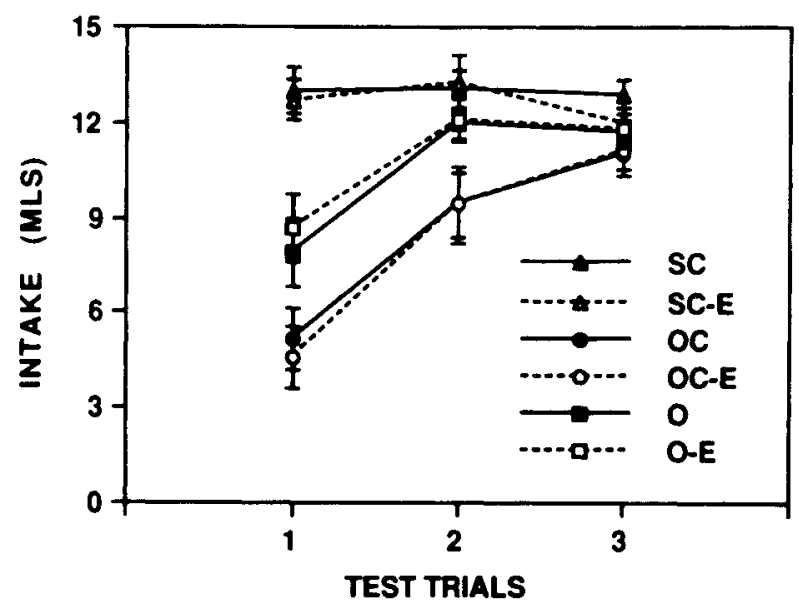

Figure 1. Mean intake of navor $X$ on the test trials in Experiment 1. Brackets indicate SEM.

The group mean intake of flavor $\mathrm{X}$ on the test trials is depicted in Figure 1, which shows that intake of flavor $\mathrm{X}$ was lowest in Groups OC and OC-E, highest in Groups SC and SC-E, and intermediate in Groups $\mathrm{O}$ and O-E. All groups increased intake over the test trials. Most striking in these results is the lack of difference between animals that had the $\mathrm{A}-\mathrm{LiCl}$ association extinguished and those that did not. A treatment (SC vs. OC vs. O) $\times$ extinction (E vs. NE) $\times$ trial ANOVA yielded a main effect of treatment $[F(2,64)=28.03, p<.001]$ and a main effect of trial $[F(2,128)=61.65, p<.001]$. Moreover, there was a treatment $\times$ trial interaction $[F(4,128)=$ $20.22, p<.001]$. There was no effect of extinction and no interaction of extinction with any other variable $(F \mathrm{~s}>1)$. On the first and second test trials, Groups OC and OC-E drank significantly less than did Groups SC and SC-E ( $p$ s $<.001$ ) and Groups $\mathrm{O}$ and O-E ( $p s<$ .002 ). Groups $\mathrm{O}$ and O-E drank less than did Groups SC and SC-E on Trial $1(p<.001)$ but did not differ from the latter groups on Trial 2 . There were no between-group differences on Trial 3.

The results of Experiment 1 show that the insertion of a second flavor during the interval between presentation of a flavor and illness reduces the conditioned aversion to the initial flavor. That is, overshadowing was observed following a single conditioning trial. Despite robust conditioned aversion and overshadowing, no effect on overshadowing of extinguishing the association between the interfering flavor and illness was observed. This absence of an effect occurred even though the results from the extinction trial indicated that extinction of flavor A was essentially complete. The present results are in agreement with those of Revusky et al. (1977), who also observed no effect of extinction of the overshadowing CS using a single conditioning trial in CTA. These results are discordant with those of Kaufman and Bolles (1981) and Matzel et al. (1985), who observed an attenuation of over- 
shadowing following multiple conditioning trials in a conditioned fear preparation.

\section{EXPERIMENT 2}

The results of Experiment 1 suggest that extinction of the overshadowing CS does not attenuate overshadowing in a single-trial CTA preparation. Experiment 2 investigated the effects of similar extinction in a multitrial overshadowing CTA procedure. There is some reason to expect that recovery of CR to an otherwise latent association will be greater with additional training of that CS prior to administering the recovery treatment. Schachtman, Gee, Kasprow, and Miller (1983) demonstrated that the unmasking of an otherwise latent association arising from a blocking procedure was more likely if the subjects had received a greater number of compound trials prior to the unmasking treatment. Since the treatments used to unmask the association in that study did not allow any obvious new learning during the recovery treatment itself, it was suggested that the unmasking occurred by enhancing the retrievability of the association between the target CS and the US. Schachtman et al. (1983) suggested that when the unmasking treatment was administered after only a few conditioning trials the retrievability of the latent association may have been so poor that treatments aimed at improving retrieval were ineffective. However, additional compound trials may have served to improve retrievability of the target CS-US association and, while the additional compound trials did not themselves increase the CR, the increased retrievability, in conjunction with that produced by the unmasking treatment, was sufficient to improve performance.

Employing this reasoning, in Experiment 2, we sought to examine whether or not additional compound training would allow greater sensitivity to recovery from overshadowing, stemming potentially from the extra conditioning. The additional training would bring the latent association closer to a threshold and allow it to become evident in performance after the overshadowing stimulus is extinguished.

\section{Method}

Subjects and Apparatus. Seventy-two experimentally naive adult male hooded rats from the colony at Northern Ilinois University served as subjects. The rats were approximately 110 days old at the start of the study and had a mean free-feeding body weight of approximately $405 \mathrm{~g}$. The subjects were maintained in the same manner as those of Experiment 1. The same materials as those of Experiment 1 were employed.

Procedure. For 3 days before the start of the experiment, all animals were allowed to drink water from the drinking tubes for $5 \mathrm{~min}$ to acclimate them to the tubes. The animals were then assigned to treatment conditions, counterbalancing for water intake on the last preliminary day; there were six treatment groups $(n s=12)$.

The general features of the conditioning procedure were the same as those in Experiment 1, except that four conditioning trials were conducted. Nonconditioned flavors were presented in isolation on odd-numbered days, and conditioned flavors were paired with illness on even-numbered days. As in Experiment 1, for half of the subjects, flavor A was Sal and flavor $\mathrm{X}$ was Suc; for the remain- ing subjects, the reverse was true. On Days 1, 3, 5, and 7, Groups $O$ and $O-E$ received distilled water in the drinking tubes for $5 \mathrm{~min}$. On these days, Groups $O C$ and $O C-E$ received $A$ for $5 \mathrm{~min}$. Groups $S C$ and SC-E received X for $5 \mathrm{~min}$. All animals received $30 \mathrm{~min}$ of water in the home cage $1 \mathrm{~h}$ following each day's treatment. On Days 2, 4, 6, and 8, Groups $O$ and $O-E$ received $X$ for $5 \mathrm{~min}$. Forty minutes later, they received $\mathrm{A}$ for $5 \mathrm{~min}$. $\mathrm{LiCl}$ injection followed the offset of $A$ by $5 \mathrm{~min}$. Due to the greater number of conditioning trials in Experiment 2 relative to that in Experiment 1 , injection volume was reduced to $0.5 \%$ body weight on all trials although a 0.3-M concentration was used again. Groups $O C$ and $O C-E$ received $\mathrm{X}$ for $5 \mathrm{~min}$. Forty minutes later, they received distilled water for $5 \mathrm{~min}$. Five minutes later, they were injected with $\mathrm{LiCl}$. Groups SC and SC-E received distilled water for $5 \mathrm{~min}$, followed $40 \mathrm{~min}$ later by a 5 -min presentation of $A$. They were injected with $\mathrm{LiCl} 5 \mathrm{~min}$ later. All animals received $30 \mathrm{~min}$ of tap water in the home cage $2 \mathrm{~h}$ following each injection.

Extinction of the overshadowing flavor, A, or presentation of water began on Day 9 and continued for 10 days. On each day, Groups O-E, OC-E, and SC-E received a 20-min exposure to A. $A$ longer exposure time was used in Experiment 2 than was used in Experiment 1 due to our expectation of a greater aversion following four conditioning trials than following the single trial used in Experiment 1. Groups O, OC, and SC received 20-min exposures to distilled water.

On Days 19 and 20, conditioned aversion to $X$ was tested. All animals received a 5 -min single-tube test. On Day 21, a similar test was conducted with A. All unspecified details were the same as those in Experiment 1 .

\section{Results and Discussion}

Intake of the nonconditioned solution (presented unpaired with illness) was as follows. Due to an error, intake was not measured on Trial 1. On Trial 2, group mean intake ranged from $7.7 \mathrm{ml}( \pm 0.4)$ to $10.0 \mathrm{ml}( \pm 0.5)$. On Trial 3, group mean intake ranged from $9.1 \mathrm{ml}( \pm 0.5)$ to $11.2 \mathrm{ml}( \pm 0.5)$. On Trial 4 , these scores ranged from $7.4 \mathrm{ml}( \pm 0.6)$ to $11.1 \mathrm{ml}( \pm 0.7)$. A treatment (OC vs. SC vs. O) $\times$ extinction (NE vs. E) $\times$ trial ANOVA on trial 2-4 showed an effect of treatment $[F(2,66)=15.75$, $p<.001]$, an effect of trial $[F(2,132)=28.11, p<$ $.001]$, and an interaction of treatment and trials $[F(4,132)$ $=3.21, p<.02]$. No other effects were significant. Between-group comparisons on each trial showed that Groups $\mathrm{O}$ and O-E drank less W than the other groups drank of the flavors $(p s<.05)$. This effect is similar to that seen in Experiment 1. Moreover, all groups, except Group SC, showed an increased intake from Trial 2 to Trial 3 and decreased intake from Trial 3 to Trial 4. These effects were revealed in separate trial ANOVAs for each treatment group $\left[F_{\mathrm{s}}(2,22) \geq 6.62, p \mathrm{~s}<.01\right]$. The source of the effect of trials on the unpaired fluid is not clear. The inverted $U$ shape of the effect argues for some systemic effect on intake during Trial 3 (e.g., motivational levels) rather than the formation of conditioned inhibition to the unpaired fluid.

Group mean intake of the first solution presented (CS1) on each conditioning trial is depicted in Figure 2. Generally, animals that received this flavor paired with illness in the absence of an interfering flavor (Groups $\mathrm{OC}$ and OC-E) showed substantial acquisition of an aversion over trials. Animals given the same first flavor paired with ill- 


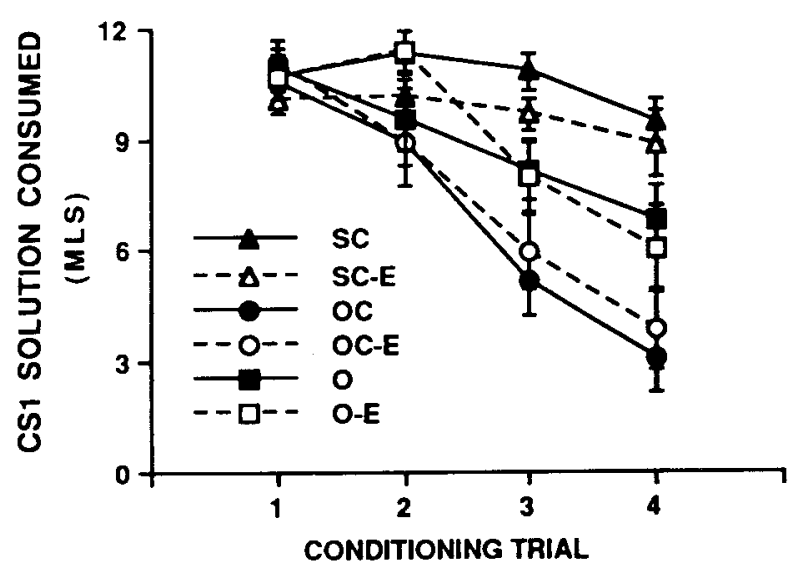

Figure 2. Mean intake of CS1 (flavor $X$ for Groups OC, OC-E, O, and O-E; water for Groups SC and SC-E) across conditioning trials in Experiment 2. Brackets indicate SEM.

ness, but also given a second, interfering flavor (Groups $O$ and $O-E$ ) acquired an aversion to CS1 more slowly. Groups SC and SC-E received only W during these presentations; their intake was stable over conditioning trials. A treatment $\times$ extinction $\times$ trial repeated measures ANOVA showed an effect of treatment $[F(2,66)=18.18, p<$ $.001]$, an effect of trial $[F(3,198)=74.53, p<.001]$, and an interaction of treatment and trial $[F(6,198)=$ $12.55, p<.001]$. There was no effect of extinction and no interaction of extinction with any other variable $(F \mathbf{s} \leq$ $1.22, p s>.20)$. All groups, except for Group SC-E, decreased their intake across trials $[F \mathrm{~s}(3,33) \geq 4.30, p \mathrm{~s}<$ $.01]$. The groups did not differ on Trial 1. Planned comparisons showed that Groups OC and OC-E drank less than did Groups SC and SC-E on Trials 2, 3, and 4 ( $p$ s $<$ .01 ) and less than did Groups $O$ and O-E on Trials 2, 3, and $4(p s<.03)$.

Group mean intake of the second solution presented (CS2) on Conditioning Trial 1 ranged from $9.1 \mathrm{ml}( \pm 0.5)$ to $10.1 \mathrm{ml}( \pm 0.5)$. On Trial 2 , intake ranged from a low of $1.2 \mathrm{ml}( \pm 0.3)$ in Group SC to $7.7 \mathrm{ml}( \pm 0.3)$ in Group OC. On Trial 3, intake ranged from $0.6 \mathrm{ml}( \pm 0.1)$ in Group SC-E to $5.1 \mathrm{ml}( \pm 0.7)$ in Group OC-E. On Trial 4, intake ranged from $0.5 \mathrm{ml}( \pm 0.03)$ in Group SC-E to $3.7 \mathrm{ml}( \pm 0.9)$ in Group OC-E. A treatment $\times$ extinction $\times$ trial ANOVA showed a main effect of treatment $[F(2,66)=34.32, p<.001]$, a main effect of trial $[F(3,198)=266.99, p<.001]$, and a treatment $\times$ trial interaction $[F(6,198)=17.84, p<.001]$. There was no effect of extinction and no interaction of extinction with any other variable $(F \mathrm{~s} \leq 1.39, p s>.20)$. All groups decreased intake over trials $\left[F_{\mathrm{S}}(3,33) \geq 5.83, \mathrm{ps}<.01\right]$. There were no differences in intake of CS2 on the first conditioning trial. Planned comparisons showed that the intake of A by Groups SC and SC-E on Trials 2, 3, and 4 was less than the intake of $W$ by Groups $O C$ and OC-E ( $p$ s $<.001$ ). Similarly, Groups $O$ and O-E drank less flavor A than Groups OC and OC-E drank W on these trials $(p s<.001)$. Groups SC and SC-E drank somewhat less than did Groups $\mathrm{O}$ and O-E on Trial $2(p<.01)$, but these groups did not differ on the remaining conditioning trials $(p s>.10)$.

On the first flavor A extinction trial, Group OC-E drank $22.3 \mathrm{ml}( \pm 0.9)$, Group SC-E drank $0.6 \mathrm{ml}( \pm 0.1)$, and Group O-E drank $0.6 \mathrm{ml}( \pm 0.1)$. By Extinction Trial 10 , Group OC-E drank $22.5 \mathrm{ml}( \pm 0.8)$, Group SC-E drank $18.7 \mathrm{ml}( \pm 1.5)$, and Group O-E drank $19.0 \mathrm{ml}$ $( \pm 1.7)$. A treatment $x$ day ANOVA on the extinction trial scores for animals receiving extinction to flavor $\mathrm{A}$ showed a main effect of treatment $[F(2,33)=39.59, p<$ $.001]$, an effect of day $[F(9,297)=56.77, p<.001]$, and an interaction of these factors $[F(18,297)=13.03$, $p<.001]$. Groups SC-E and O-E significantly increased their intake of flavor A over trials $[F \mathrm{~s}(9,99) \geq 2.91$, ps $<.001]$, whereas Group OC-E maintained high stable intake of flavor A over the course of the trials $(p>.20)$. Group OC-E drank more than did Groups SC-E and O-E on all extinction trials except Trial 10 ( $p s<.001)$. Groups SC-E and O-E did not differ on intake of flavor A during extinction $(p s<.10)$.

Group mean intake of $X$ on the test trials is shown in Figure 3. The pattern of results is similar to that observed in Experiment 1. Groups OC and OC-E drank the least on both trials, indicating a substantial aversion to flavor $\mathrm{X}$. Groups SC and SC-E showed no aversion to flavor X; intake was high and stable over the two test trials. Groups $O$ and O-E drank an amount intermediate to the other treatment conditions. Thus, the overshadowing effect that was evident during the conditioning trials was also manifest on the test trials. The prior extinction of the flavor A- $\mathrm{LiCl}$ association had no effect on test-trial consumption of flavor $\mathrm{X}$ in any of the treatment conditions. These impressions were supported statistically. A treatment $X$ extinction $\times$ trial ANOVA indicated a main effect of treatment $[F(2,66)=32.80, p<.001]$ and an effect of trial $[F(1,66)=125.55, p<.001]$. No other effects or interactions, including those involving extinction, were significant. Planned comparisons showed that Groups OC and

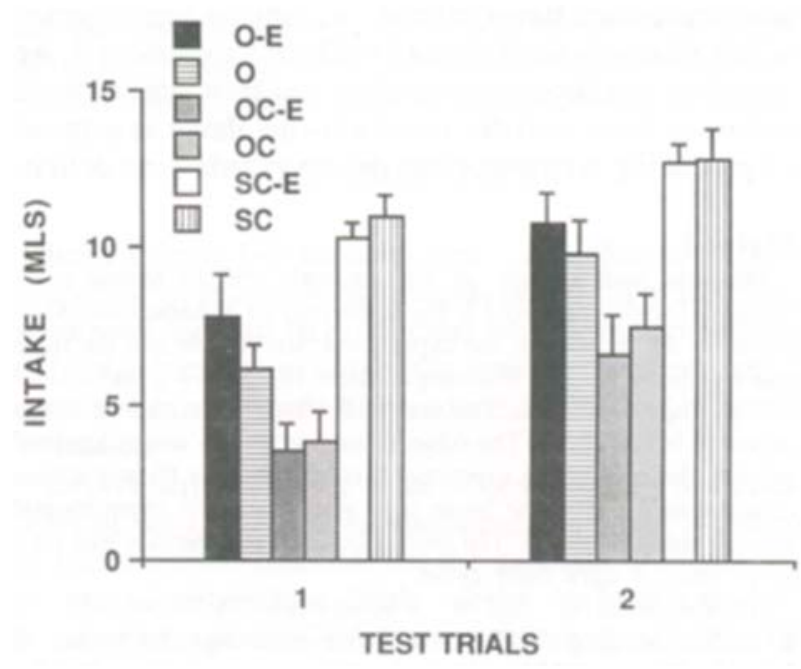

Figure 3. Mean intake of flavor $X$ on the test trials in Experiment 2. Brackets indicate SEM. 
OC-E drank less than did Groups SC and SC-E on both test trials ( $p s<.001)$. Groups OC and OC-E drank less than did Groups $\mathrm{O}$ and $\mathrm{O}-\mathrm{E}$ on these trials $(p s<.002)$. Groups $\mathrm{O}$ and O-E drank less than did Groups SC and SC-E $(p s<.003)$.

The results of Experiment 2 are consistent with those of Experiment 1: extinction of the overshadowing stimulus did not modify overshadowing. Using the present parameters, the absence of an extinction effect occurs with either one-trial or multitrial compound conditioning.

\section{EXPERIMENT 3}

In Experiment 3, we again attempted to produce recovery from overshadowing, but we used a training procedure to obtain overshadowing that was different from the training procedure used in Experiment 1 and 2 . In the previous experiments, we obtained no evidence of recovery from overshadowing. Any effort to support a null result mandates the use of a range of parameters as a means of maximizing sensitivity to obtain an effect of posttraining extinction of the overshadowing stimulus.

The procedures used in Experiments 1 and 2 were such that substantial conditioning could be expected in subjects trained with the target flavor in the absence of an overshadowing stimulus (i.e., Groups $O C$ and OC-E). The extent of such conditioning was then attenuated in the overshadowing groups by the presence of the overshadowing stimulus. In Experiment 3, we sought to use a procedure that would weaken the association between the target flavor and the US to examine if such training would allow recovery to occur. Such a condition might produce a more "malleable" association. In Experiment 3, we used a procedure similar to that employed previously to obtain overshadowing in CTA (Kaye et al., 1988). In this procedure, subjects that received compound conditioning were exposed to the target flavor for $10 \mathrm{~min}$. Three and one-half hours after the first flavor exposure, subjects received 30-min exposure to a second flavor. Immediately after this second flavor experience, subjects were injected with a relatively weak dose of $\mathrm{LiCl}$. In Experiment 3, we used this conditioning procedure and then administered extinction trials with the overshadowing flavor as a means of producing recovery from the overshadowing deficit.

\section{Method}

Subjects and Apparatus. Fifteen male and 14 female adult Sprague-Dawley rats bred at the University of Missouri served as subjects. At the start of the experiment, the female and the male rats had body weights that ranged from 187 to $274 \mathrm{~g}$ and 233 to $321 \mathrm{~g}$, respectively. Each rat was individually housed with ad-lib access to lab rat chow. The subjects were gradually water deprived prior to the start of the experiment, culminating in 10-min access to water each day in the home cage after that day's experimental session was completed. The colony housing the animals was on a 16-h light:8-h dark daily cycle.

All treatments occurred in the home cage. The home cage was a standard hanging stainless steel, wire-mesh cage that measured $24 \times 18 \times 18 \mathrm{~cm}$. All experimental solutions were delivered to the subjects in a drinking tube that was made from a modified $50-\mathrm{ml}$ plastic syringe with a metal spout. Two flavors were used in this experiment: $3 \%(v / v)$ cider vinegar (Vin) and $12 \%(w / v)$ sucrose (Suc). The US was a $1 \%$ body-weight i.p. injection of $0.15-\mathrm{M} \mathrm{LiCl}$.

Procedure. One third of the subjects were assigned to Group $O C$ $(n=10)$; the remaining rats were later assigned to an overshadowing condition that included Groups $\mathrm{O}$ and $\mathrm{O}-\mathrm{E}$ (the differentiation of subjects into Groups $\mathrm{O}$ and $\mathrm{O}-\mathrm{E}$ was based on intake during subsequent conditioning trials). Vin, designated $\mathrm{X}$, served as the target solution for all subjects. For subjects that experienced Suc on the conditioning trials, Vin served as the overshadowed stimulus and Suc, designated A, served as the overshadowing stimulus. On Days 1 and 3 , all subjects received 10 -min access to $X$. Two hundred minutes after access to $X$ terminated, animals in Group $O C$ received 30-min access to water and the remaining animals received $A$. After this 30 -min period, the animals were injected with $\mathrm{LiCl}$. Throughout the experiment, all drinking solutions given during experimental treatments were recorded by weighing the drinking tubes before and after fluid delivery. Approximately $2 \mathrm{~h}$ after the injection, each animal received 10-min access to water. If an animal did not drink at least $2 \mathrm{ml}$ of the initial solution of the day's treatment on its first exposure to that solution, the animal was removed from the experiment. In practice, no subjects were lost on the basis of this criterion.

On Days 2 and 4 , the animals were given no treatments except their daily access of water to ensure recovery from illness. Following Day 3, the animals that had been given both $X$ and $A$ on the conditioning trials were assigned to one of two groups: Group $O$ $(n=9)$ and Group O-E $(n=10)$, counterbalanced for body weight, sex, and consumption of $\mathrm{X}$ on the conditioning trials.

On Days 5-7, animals in Groups $O C$ and $O$ received a 15-min exposure to water-filled drinking tubes, and the subjects in Group O-E received a similar exposure to $A$, the overshadowing stimulus, rather than water. On Days 8-10, all subjects were tested for their consumption of $X$ during a 15-min exposure. All other details were the same as those in Experiments 1 and 2.

\section{Results and Discussion}

Group mean consumption of $\mathrm{X}$ on the two conditioning trials was $9.7 \mathrm{ml}( \pm 1.0)$ and $12.5 \mathrm{ml}( \pm 0.7), 9.5 \mathrm{ml}$ $( \pm 0.9)$ and $9.0 \mathrm{ml}( \pm 0.7)$, and $9.5 \mathrm{ml}( \pm 0.9)$ and $12.0 \mathrm{ml}( \pm 1.1)$, on the first and second trials for Groups $\mathrm{O}, \mathrm{OC}$, and O-E, respectively. An ANOVA conducted on these scores with group and trials as factors indicated no main effect of group $(p>.20)$, but there was an effect of trial and a significant interaction of these factors $(F \geq 8.67, p s<.002)$. The interaction arose because group differences did not occur on the first conditioning trial $(F<1)$, but the groups differed on Trial $2[F(1,26)$ $=4.63, p<.02]$. Group OC drank less $\mathrm{X}$ on Trial 2 than did the other groups ( $p s<.05$ ), but Groups $O$ and $O-E$ did not differ from each other $(F s<1)$, an effect indicative of overshadowing of $\mathrm{X}$ by $\mathrm{A}$ in Groups $\mathrm{O}$ and O-E.

Simple main effects tests examining each group's consumption of Vin across days yielded no significant decrease for any of the conditions, indicating that more than one conditioning trial was necessary to obtain clear evidence of an aversion to $X$. That is, consumption of $X$ did not decrease from the first to the second conditioning trial. In fact, Groups $\mathrm{O}$ and $\mathrm{O}-\mathrm{E}$ showed a significant increase in consumption across the two trials $(p<.005)$, an effect likely due to lessening of neophobia. Group OC did not increase consumption across trials $(F<1)$. This absence of a change in consumption of $\mathrm{X}$ in Group $\mathrm{OC}$ and 
the presence of such a change in the other groups raises the possibility that a small amount of conditioning did occur as a result of Trial 1 for Group OC, and this conditioning was sufficient to offset any increase in consumption on the second trial that would have otherwise occurred due to an attenuation of neophobia. The weaker conditioning in Groups $\mathrm{O}$ and $\mathrm{O}-\mathrm{E}$ allowed the attenuation of neophobia to be observed.

Group mean consumption of the second flavor presented (A for Groups O and O-E, water for Group OC) on the two conditioning trials was $13.6 \mathrm{ml}( \pm 1.3)$ and $2.0 \mathrm{ml}$ $( \pm 0.5), 11.4 \mathrm{ml}( \pm 0.8)$ and $9.3 \mathrm{ml}( \pm 0.9)$, and $13.0 \mathrm{ml}$ $( \pm 1.3)$ and $2.0 \mathrm{ml}( \pm 0.4)$ on the first and second trials for Groups O, OC, and O-E, respectively. An ANOVA conducted on these scores indicated main effects of group and trial $(F \mathrm{~s} \geq 3.96, p \mathrm{~s}<.05)$ and a significant interaction $[F(2,276)=29.16, p<.0001]$. The interaction occurred because groups did not differ on the first conditioning trial $(p>.20)$, but did differ on the second trial $[F(1,26)=128.52, p<.001]$. These group differences arose because consumption of $\mathrm{A}$ was similar in Groups $\mathrm{O}$ and $\mathrm{O}-\mathrm{E}$, but consumption by both these groups was much less than the amount of water consumed by Group $O C$ $(p s<.01)$. Simple main effects tests examining each group's consumption across days of the fluid they were exposed to prior to the injection yielded a significant decrease in all conditions ( $p s<.02$ ), including the amount of water consumed by Group OC. The latter effect, which is certainly smaller than the decrease in A intake across trials exhibited by Groups $O$ and O-E, could have been the result of an aversion to consuming fluid from the experimental drinking tube.

During extinction, Group O-E consumed $1.0 \mathrm{ml}$ $( \pm 0.2), 4.2 \mathrm{ml}( \pm 1.2)$, and $10.4 \mathrm{ml}( \pm 2.4)$ of sucrose on Trials 1,2 , and 3 , respectively. Group $O$ consumed $14.0 \mathrm{ml}( \pm 1.0), 14.5 \mathrm{ml}( \pm 1.2)$, and $15.5 \mathrm{ml}( \pm 1.1)$ of water on these three trials. Group OC drank $8.7 \mathrm{ml}$ $( \pm 1.2), 10.7 \mathrm{ml}( \pm 1.1)$, and $13.8 \mathrm{ml}( \pm 1.3)$ of water on these three trials. A group $\times$ trial ANOVA conducted on the extinction data revealed significant main effects of group, trial, and an interaction $(p s<.001)$. These differences occurred because Group O-E drank little $A$ at the beginning of the extinction phase, whereas the other groups drank relatively large amounts of water. Group $O C$ consumed less water at the outset of extinction than did Group $\mathrm{O}$, an effect that suggests the formation of an unintended aversion to water in Group OC. Group O-E significantly increased intake of $A$ over the course of extinction. Likewise, Group OC showed a significant increase in intake of water over these trials $(p s<.001)$. Group $O$ showed a high level of water intake from the outset of extinction and thus did not increase their intake over trials $(p<.10)$. These findings indicate that the overshadowing stimulus was extinguished after compound conditioning and before testing of $\mathrm{X}$ in Group O-E.

The consumption of $\mathrm{X}$ on the test trials is depicted in Figure 4. These group means show that none of the groups exhibited a strong aversion to $X$. However, Group $O$ consumed more $\mathrm{X}$ than did Group OC, suggesting an over-

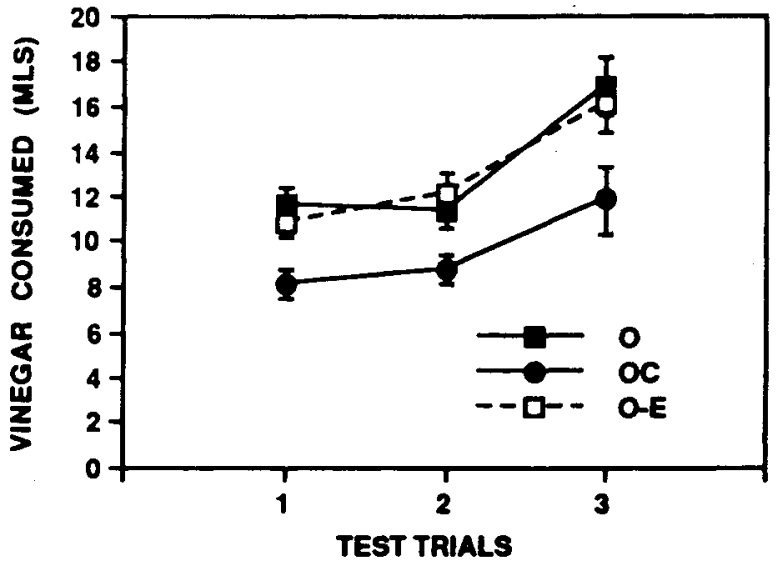

Figure 4. Mean intake of vinegar $(X)$ on the test trials in Experiment 3. Brackets indicate SEM.

shadowing of $\mathrm{X}$ by $\mathrm{A}$ in Group O. Moreover, Groups $\mathrm{O}$ and $O-E$ were very similar in their consumption, suggesting no effect of extinction of A prior to testing. These claims were supported by statistical analyses; a group $X$ trial ANOVA conducted on the test data yielded a main effect of group $[F(2,26)=6.38, p<.006]$, trial $[F(2,26)$ $=40.98, p<.001]$, but no interaction of these factors $(p<.20)$. Group comparisons revealed that Group 0 drank significantly more $\mathrm{X}$ than did Group $\mathrm{OC}[F(1,17)$ $=9.85, p<.01]$; Group O-E also drank more than did Group $O C[F(1,18)=9.05, p<.01]$. Groups $O$ and $\mathrm{O}-\mathrm{E}$ did not differ $(F<1)$.

The results of Experiment 3 are consistent with those of Experiments 1 and 2: postconditioning extinction of the overshadowing stimulus had no effect on the magnitude of overshadowing. This was observed despite the use of a procedure that employed a relatively low dose of $\mathrm{LiCl}$, few conditioning trials, and a long interstimulus interval between the overshadowed stimulus and the US. This procedure presumably produced an overshadowed association that was weak and therefore one that might have been more sensitive to manipulations, such as postconditioning extinction of the overshadowing stimulus.

\section{EXPERIMENT 4}

Experiments 1-3 failed to obtain an effect of extinction of the overshadowing stimulus on the CR to the overshadowed stimulus. It is not clear why these experiments did not achieve an effect, while previous studies using a conditioned suppression procedure obtained an effect of extinction.

Experiments 1-3 used serial nonoverlapping presentations of the CS during conditioning. This was intended to minimize the potential for the acquisition of withincompound associations. Such associations have been documented to occur in CTA and to occur more readily with simultaneous presentations of the CSs (e.g., Rescorla, $1980,1982)$. However, serial CS presentation during compound conditioning may reduce sensitivity to the ef- 
fects of extinction on enhancing conditioned responding to the target CS. The view of the extinction effect obtained by Kaufman and Bolles (1981) taken by comparator models is that the overshadowing CS, A, serves as the background stimulus context or the "comparator term" for the overshadowed CS, $X$, during conditioning (Matzel et al., $1985,1987)$. It may be that $A$ and $X$ must overlap in order for the former cue to serve as the context for the latter stimulus. Matzel et al. (1987) demonstrated that one can achieve an effect of extinction of $A$ on the $C R$ to $X$ when $A$ and $X$ have been conditioned as a serial compound in a conditioned suppression procedure in which the CSs have overlapped but the onset of $A$ has preceded that of $X$. However, serial presentation may not be adequate to engender A with the status of a comparator term in a CTA procedure, particularly the nonoverlapping compound of the present Experiments 1-3.

In Experiment 4, we sought to test the effects of extinction of $A$ on the CR to X, using a simultaneous CS compound conditioning procedure. The procedure was otherwise very similar to that of Experiment 2.

\section{Method}

Subjects and Apparatus. Forty-two female and 30 male experimentally naive adult Sprague-Dawley-derived rats from the colony at the University of Missouri served as subjects. The males ranged from 357 to $560 \mathrm{~g}$ in body weight; the females ranged from 256 to $452 \mathrm{~g}$. The subjects were maintained in the same manner as those of Experiment 3. The same materials as those of Experiment 3 were employed.

Procedure. There were six treatment groups $(n s=12)$. The general features of the conditioning procedure were the same as those in Experiment 2, except that a simultaneous CS presentation was used. Nonconditioned flavors were presented alone on odd-numbered days during conditioning, and conditioned flavors were paired with illness on even-numbered days. On Days 1, 3, 5, and 7, Groups $O$ and $O-E$ received water in the drinking tubes for $5 \mathrm{~min}$. On these days, Groups $O C$ and $O C$-E received $1 \% \mathrm{Sal}$ (A) for $5 \mathrm{~min}$. Groups SC and SC-E received 5\% Suc (X) for $5 \mathrm{~min}$. All animals received $10 \mathrm{~min}$ of water in the home cage $1 \mathrm{~h}$ following each day's treatment. On Days 2, 4, 6, and 8, Groups $O$ and O-E received a simultaneous CS compound flavor composed of equal amounts of $\mathrm{A}$ and $\mathrm{X}$ for $5 \mathrm{~min}$. A 0.3-M 0.5\% body-weight $\mathrm{LiCl}$ injection followed the flavor by $5 \mathrm{~min}$. Groups $O C$ and OC-E received $X$ for $5 \mathrm{~min}$. Five minutes later, these subjects were injected with $\mathrm{LiCl}$. Groups $\mathrm{SC}$ and SC-E received Sal for $5 \mathrm{~min}$ and were injected with $\mathrm{LiCl}$ 5 min later. All animals received 10 min of tap water in the home cage $2 \mathrm{~h}$ following each injection.

Extinction of the overshadowing flavor, A, or presentation of water began on Day 9 and continued for 18 days. On each day, Groups O-E, OC-E, and SC-E received a 5 -min exposure to A. Groups $\mathrm{O}, \mathrm{OC}$, and $\mathrm{SC}$ received 5-min exposures to water.

On Days 27-33, conditioned aversion to $X$ was tested. All animals received a 5-min single-tube test. On Day 34, a similar test was conducted with A. All unspecified details were the same as those in Experiment 2.

\section{Results and Discussion}

Group mean intake of flavored solutions on Days 1, 3, 5 , and 7 ranged from $4.7 \mathrm{ml}( \pm 1.0)$ to $8.9 \mathrm{ml}( \pm 0.9)$ of $A$ by the $\mathrm{OC}$ groups, and from $6.7 \mathrm{ml}( \pm 1.4)$ to $11.0 \mathrm{ml}( \pm 1.0)$ of $X$ by the $S C$ groups. A treatment (OC vs. SC vs. O) $\times$ extinction (NE vs. E) $\times$ trial ANOVA on the fluids consumed on these days showed an effect of treatment $[F(2,66)=9.55, p<.005]$. No other effects were significant. Between-group comparisons on each trial showed that Groups SC and SC-E drank more Suc than the other groups drank of their solutions $(p s<.01)$.

On each of the four conditioning trials, mean intake of the CS solution for animals in the OC conditions combined were $7.6 \mathrm{ml}( \pm 0.9), 2.2 \mathrm{ml}( \pm 0.4), 3.3 \mathrm{ml}( \pm 0.7)$, and $0.5 \mathrm{ml}( \pm 0.1)$, respectively. Group means for the SC conditions on the trials were $6.4 \mathrm{ml}( \pm 1.0), 4.1 \mathrm{ml}$ $( \pm 0.9), 5.4 \mathrm{ml}( \pm 1.1)$, and $1.6 \mathrm{ml}( \pm 0.7)$. These values for the $O$ conditions were $7.9 \mathrm{ml}( \pm 0.5), 1.5 \mathrm{ml}( \pm 0.2)$, $2.5 \mathrm{ml}( \pm 0.6)$, and $0.7 \mathrm{ml}( \pm 0.1)$. A treatment $\times$ extinc tion $\times$ trial repeated measures ANOVA showed an effect of treatment $[F(2,66)=4.45, p<.02]$, an effect of trial $[F(3,198)=44.72, p<.0001]$, and an interaction of treatment and trial $[F(6,198)=2.19, p<.05]$. There was no effect of extinction and no interaction of extinction with any other variable $(F \mathrm{~s}<1)$. The main effect of treatment occurred because Groups SC and SC-E produced somewhat slower conditioning than did the other groups $\left[F_{\mathrm{S}}(1,66)>4.91, p \mathrm{~s}<.05\right]$. This was particularly evident on Trials 2 and 3 .

On the first A extinction trial, Group OC-E drank $6.6 \mathrm{ml}( \pm 1.3)$, Group SC-E drank $0.5 \mathrm{ml}( \pm 0.1)$, and Group O-E drank $0.5 \mathrm{ml}( \pm 0.1)$. The small amount consumed by Group SC-E (which received A-illness pairings), relative to the large intake by Group OC-E (which received $X$-illness trials), indicates that there was little stimulus generalization between $\mathrm{A}$ and $\mathrm{X}$. By Extinction Trial 18, Group OC-E drank $12.1 \mathrm{ml}( \pm 1.4)$, Group SC-E drank $9.7 \mathrm{ml}( \pm 1.7)$, and Group O-E drank $10.5 \mathrm{ml}$ $( \pm 1.7)$. A treatment $\times$ trial ANOVA on the data from the first and last extinction trials for these groups showed a main effect of treatment $[F(2,33)=6.30, p<.005]$, an effect of trial $[F(1,33)=76.43, p<.0001]$, and no interaction of these factors $(p<.10)$. This main effect of group occurred because Group OC-E did not show an aversion to $A$, and the subjects in this group drank more than did the subjects in Groups O-E and SC-E $[F \mathrm{~s}(1,33)>8.52, p<.01]$. Groups SC-E and O-E did not differ $(F<1)$.

Group mean intake of $X$ on the test trials is shown in Figure 5. Groups OC and OC-E drank the least on the test trials, indicating a substantial aversion to flavor $\mathrm{X}$.

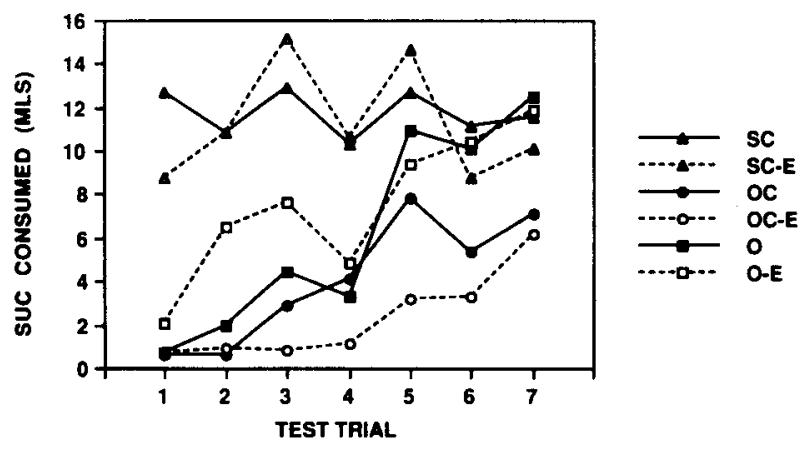

Figure 5. Mean intake of sucrose $(X)$ on the test trials in Experiment 4. Brackets indicate SEM. 
Groups SC and SC-E showed no aversion to X. Groups $O$ and $O-E$ drank an amount intermediate to the other treatment conditions. Thus, the overshadowing effect that was evident during the conditioning trials was also found on the test trials. A treatment $\times$ extinction $\times$ trial ANOVA conducted on the scores in Figure 5 indicated a main effect of treatment $[F(2,66)=40.91, p<.0001]$ and an effect of trial $[F(6,396)=19.45, p<.0001]$. There was no effect of extinction $(F<1)$ and no interaction of extinction with any other factor, including the three-way interaction ( $p s>.15$ ). There was a treatment $\times$ trial interaction $[F(12,396)=6.32, p<.0001]$.

Planned simple factorial analysis of Groups $\mathrm{O}$ and $\mathrm{OC}$ revealed a significant treatment $\times$ trial interaction $[F(6,132)=2.38, p<.05]$. This interaction occurred because Group $O$ extinguished more rapidly than did Group OC. This effect indicates that overshadowing occurred. An additional planned simple factorial analysis of Groups $\mathrm{O}$ and $\mathrm{OE}$ found no main effect of treatment $(F<1)$, but there was a strong tendency toward an interaction $[F(6,132)=2.14, p=.053]$. This interaction stemmed from more rapid extinction by Group O-E than by Group $O$. This suggestive difference indicates that extinction of $\mathrm{A}$, the overshadowing stimulus, attenuated the CR to $X$. This effect is consistent with extinction of $A$ degrading an $\mathrm{A}-\mathrm{X}$ within-compound association rather than producing the effect obtained by Matzel et al. (1985, 1987) and Kaufman and Bolles (1978) using a conditioned suppression procedure. A similar planned simple factorial ANOVA conducted on Groups OC and OC-E obtained no main effect of group, and no groups $\times$ trial interaction occurred $(p>.15)$.

Groups O, O-E, OC, OC-E, SC, and SC-E consumed $9.5 \mathrm{ml}( \pm 1.2), 12.1 \mathrm{ml}( \pm 1.0), 12.3 \mathrm{ml}( \pm 0.5), 12.1 \mathrm{ml}$ $( \pm 0.5), 3.1 \mathrm{ml}( \pm 1.3)$, and $10.9 \mathrm{ml}( \pm 1.3)$ of Sal on Day 34. An ANOVA conducted on these scores revealed a treatment $\times$ extinction interaction $[F(2,66)=7.76, p<$ $.001]$. It is clear from the group means that this interaction stemmed from the low intake by Group SC (relative to that of the other conditions), as would be expected, since these subjects received conditioning with Sal, but no extinction with Sal. The high consumption by Group $O$ is surprising, but it is possible that $A$ was somewhat overshadowed by $X$. It is also possible that the prior test on $X$ obscured the aversion to $A$.

The results of Experiment 4 are consistent with those of Experiments 1-3: extinction of the overshadowing stimulus did not decrease overshadowing-on the contrary, extinction of the overshadowing stimulus decreased the CR to the overshadowed CS. Thus, the absence of an extinction effect on attenuating overshadowing is not confined to serial CS compound presentations.

\section{EXPERIMENT 5}

In Experiment 4, we obtained no effect of extinction of $A$ on the $C R$ to $X$ using a simultaneous compound CS during conditioning. The use of four conditioning trials in Experiment 4 might have been insensitive to producing an increase in $C R$ with extinction of $A$ if the four trials allowed the development of $\mathrm{A}-\mathrm{X}$ associations. To further substantiate the failure of extinction to attenuate overshadowing with a simultaneous compound CS, we used two conditioning trials in Experiment 5. Fewer conditioning trials may decrease the development of $\mathrm{A}-\mathrm{X}$ associations and enhance the potential for obtaining an increase in $\mathrm{CR}$ to $\mathrm{X}$ after $\mathrm{A}$ extinction.

\section{Method}

Subjects and Apparatus. Thirteen male and 19 female adult Sprague-Dawley rats served as subjects. At the start of the study, the female and male rats had body weights that ranged from 266 to $336 \mathrm{~g}$ and 433 to $640 \mathrm{~g}$, respectively. The rats were obtained, housed, and maintained as in Experiment 4. The apparatus was the same as that of Experiment 4, except that the $0.3-\mathrm{M} \mathrm{LiCl}$ was administered at $1 \%$ body weight rather than at $0.5 \%$ body weight.

Procedure. The procedure of Experiment 5 was identical to that of Experiment 4, except for the following changes. Experiment 5 included only two conditioning trials and only six extinction trials; there were no SC conditions included in this study. One half of the subjects were assigned to Groups OC and OC-E $(n=8)$; the remaining rats were assigned to an overshadowing condition that included Groups $O$ and $O-E$ (the differentiation of subjects into Groups $O C$ and $O C-E$ and Groups $O$ and O-E was based on intake during subsequent conditioning trials). As in Experiment 4, Suc served as the target solution (X) and Sal served as the overshadowing stimulus (A) for Groups $O$ and $O-E$. On Days 1 and 3, subjects in Groups $O C$ and $O C$-E received 5-min access to $A$, and Groups $\mathrm{O}$ and $\mathrm{O}-\mathrm{E}$ received 5-min exposure to water. No $\mathrm{LiCl}$ was administered on Days 1 and 3. On Days 2 and 4, subjects in Groups $O C$ and $O C-E$ received a 5-min exposure to $X$, followed $5 \mathrm{~min}$ later by $\mathrm{LiCl}$. The subjects in Groups $\mathrm{O}$ and $\mathrm{O}-\mathrm{E}$ received the same treatment as Groups $O C$ and $O C-E$, except that the CS was a compound CS flavor of $A$ and X. Approximately $2 h$ after the injection, each animal received 10-min access to water. Following Day 3, the animals that had been given both $\mathrm{X}$ and $\mathrm{A}$ on the conditioning trials were assigned to one of two groups: Group $O(n=8)$ and Group O-E $(n=8)$, counterbalanced for body weight, sex, and consumption on the conditioning trials.

On Days 5-10, animals in Groups $O C$ and $O$ received a 5-min exposure to water-filled drinking tubes, and the subjects in Group O-E received a 5-min exposure to A. On Days 11-16, all subjects were tested for their consumption of $\mathrm{X}$ during a 5-min exposure. All other details were the same as those in Experiment 4. On Day 17, a similar test was conducted with $\mathrm{A}$.

\section{Results and Discussion}

One subject in Group O-E became ill and was discarded from the experiment. Group mean consumption of the flavored solution on the two conditioning trials was $9.9 \mathrm{ml}$ $( \pm 1.2)$ and $1.7 \mathrm{ml}( \pm 0.5)$ for Group $\mathrm{O}$ and $10.7 \mathrm{ml}$ $( \pm 1.3)$ and $1.7 \mathrm{ml}( \pm 0.5)$ for the Group O-E on the first and second trial, respectively. Consumption of the solution on these trials was $8.9 \mathrm{ml}( \pm 0.8)$ and $1.7 \mathrm{ml}( \pm 0.5)$ for Group $O C$ and $9.8 \mathrm{ml}( \pm 1.0)$ and $1.9 \mathrm{ml}( \pm 0.5)$ for Group OC-E. An ANOVA conducted on the scores, with treatment, extinction condition, and trial as factors, indicated an effect of trial $[F(1,27)=255.50, p<.0001]$, but no other main effects or interactions $\left(F_{\mathrm{s}}<1\right)$. $\mathrm{O}$ and $O C$ conditions did not differ in consumption on the conditioning trials. 
Group mean consumption of the flavor presented on Days 1 and 3 was $10.6 \mathrm{ml}( \pm 0.9)$ and $7.2 \mathrm{ml}( \pm 1.2)$ for Group $O$ and $11.9 \mathrm{ml}( \pm 1.2)$ and $8.3 \mathrm{ml}( \pm 2.1)$ for Group O-E, respectively. Consumption on these days was $9.1 \mathrm{ml}( \pm 0.8)$ and $4.9 \mathrm{ml}( \pm 1.1)$ for Group OC and $10.8 \mathrm{ml}( \pm 1.5)$ and $3.9 \mathrm{ml}( \pm 1.3)$ for Group OC-E, respectively. An ANOVA using treatment, extinction condition, and trial as factors conducted on the amount of water consumed by the $O$ conditions and the amount of flavor consumed by the $\mathrm{OC}$ conditions indicated main effects of treatment and trial $(F \mathrm{~s} \geq 6.01, p s<.03)$, but no other main effects or interactions were obtained $(F \mathrm{~s}<1)$. This main effect of treatment occurred because more water was consumed by the rats in the $O$ conditions than $A$ by the rats in the OC conditions. The decrease in consumption of the flavor by OC conditions on Day 3 is anomalous. It may reflect a general decrease in thirst since all but 2 of the rats in the $\mathrm{O}$ conditions drank less water on Day 3 than they did on Day 1.

During extinction, Group O-E consumed $0.7 \mathrm{ml}( \pm 0.1)$ and $6.5 \mathrm{ml}( \pm 1.9)$ of $A$ on the first and sixth extinction trials, respectively. Group OC-E consumed $4.5 \mathrm{ml}$ $( \pm 1.4)$ and $8.5 \mathrm{ml}( \pm 1.8)$ of $A$ on the first and sixth extinction trials, respectively. A group $x$ day ANOVA conducted on the extinction data revealed significant main effects of group and trial and an interaction $(F \mathrm{~s} \geq 4.69$, $p \mathrm{~s}<.002$ ). There was no difference in consumption between Groups O-E and OC-E on the last extinction trial $(F<1)$. These findings indicate that the overshadowing stimulus was extinguished after compound conditioning and before testing.

The consumption of $\mathrm{X}$ on the test trials is depicted in Figure 6. Group $O$ consumed more $X$ than Group OC, revealing an overshadowing of $X$ by $A$ in Group $O$. A treatment $(\mathrm{O}$ vs. $\mathrm{OC}) \times$ extinction condition $\times$ trial ANOVA conducted on the $\mathrm{X}$ test data yielded a main effect of treatment $[F(1,27)=20.45, p<.0002]$, extinction $[F(1,27)=5.19, p<.05]$, and day $[F(4,108)=$

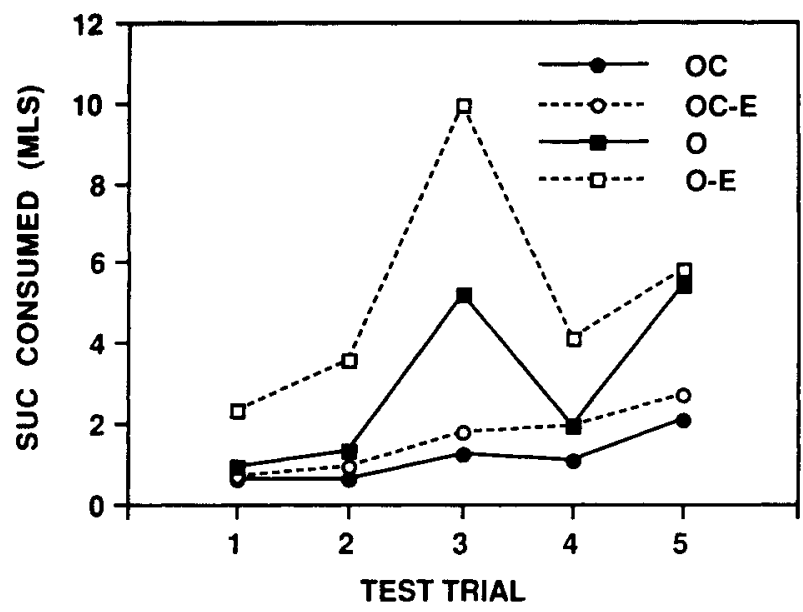

Figure 6. Mean intake of sucrose $(X)$ on the test trials in Experiment 5. Brackets indicate SEM.
$11.18, p<.0001]$. The only significant interaction was treatment $\times$ day $[F(4,108)=5.08, p<.001]$. The treatment effect indicates that the $O$ groups consumed more $\mathrm{X}$ than did the OC groups. Specific comparison of Groups $O$ and $O C$ using a group $\times$ day ANOVA yielded a main effect of group $[F(1,14)=4.98, p<.05]$. These results demonstrate that overshadowing occurred.

A group $\times$ day ANOVA comparing Groups $\mathrm{O}$ and $\mathrm{O}-\mathrm{E}$ obtained a main effect of group $[F(1,13)=5.29, p<.05]$. This difference arose because extinction of $A$ reduced the aversion to $\mathrm{X}$ for Group O-E relative to that for Group $\mathrm{O}$.

Groups O, O-E, OC, OC-E consumed $0.4 \mathrm{ml}( \pm 0.1)$, $4.3 \mathrm{ml}( \pm 1.6), 4.3 \mathrm{ml}( \pm 1.2)$, and $4.8 \mathrm{ml}( \pm 1.6)$ of Sal on the test trial on Day 17. An ANOVA conducted on these scores revealed no significant effects.

Planned simple factorial analysis of Groups $\mathrm{OC}$ and OC-E obtained no main effect of group and no group $X$ trial interaction $(F \mathrm{~s}<1)$.

The results of Experiment 5 are consistent with those of Experiments 1-4: postconditioning extinction of the overshadowing stimulus failed to reduce the magnitude of overshadowing. Rather, extinction of A for Group O-E served to decrease the CR to $X$.

\section{GENERAL DISCUSSION}

The present series of experiments demonstrated overshadowing when a second flavor was presented during the interval between the presentation of a target flavor and illness (Experiments 1-3) and with a simultaneous compound CS (Experiments 4 and 5). The primary purpose of these experiments was to examine the modulatory effects of extinction of the overshadowing CS on the magnitude of the overshadowing effect. Extinction of the overshadowing CS consistently failed to decrease overshadowing following single-trial (Experiment 1) or multitrial (Experiments 2-5) overshadowing and following serial (Experiments 1-3) and simultaneous (Experiments 4 and 5) compound CSs. Experiments 1 and 2 used conditioning parameters that produced relatively strong aversions to the target and interfering flavors. Although there was an unambiguous indication that the association between the overshadowing flavor and the US was extinguished before testing, overshadowing was unaffected. Experiment 3 replicated these findings using two conditioning trials and a long target flavor-US interval that produced a relatively weak aversion to the target flavor. This was done with the intention of producing a potentially more malleable association. Despite this attempt, the magnitude of overshadowing between extinguished and nonextinguished subjects was the same. In Experiments 4 and 5 , we used simultaneous compound trials and found that extinction of the overshadowing CS decreased the CR to the overshadowed CS, suggesting that conditioning produced within-compound associations.

The present results agree with those of Revusky et al. (1977), who found that extinction of the overshadowing flavor did not attenuate the overshadowing deficit. The present 
experiments corroborated this result and included the additional control groups for overshadowing (Group OC) that were omitted by Revusky et al.

In Experiments 4 and 5, we found that extinction of the overshadowing CS weakened the aversion to the overshadowed CS. These results are consistent with the observations of Speers et al. (1980) that such extinction enhances overshadowing (i.e., decreases conditioned responding to the overshadowed flavor) through the weakening of the association between the overshadowed and the overshadowing flavors (i.e., within-compound associations). Similar to the procedure used in Experiments 4 and 5, Speers et al. used a simultaneous flavor compound. In contrast, Experiments 1-3 obtained no evidence of withincompound associations when a serial compound was used. The serial mode of CS presentation should be less likely to produce within-compound associations; thus, extinction of one element would not be expected to weaken the aversion to the other element (Rescorla, 1980, 1982).

The present research consistently showed that extinction of the overshadowing flavor in CTA does not attenuate, and, under certain conditions, it enhances overshadowing. However, there have been reports of an attenuation of multitrial overshadowing in conditioned fear preparations (Kaufman \& Bolles, 1981; Matzel et al., $1985,1987)$. The critical question is: What accounts for the differences between those studies and the current taste aversion experiments?

First, it is possible that the number of conditioning trials is important, and that the current experiments did not include enough conditioning trials in the multitrial experiments. It is possible that overshadowing would have been attenuated by extinction of the overshadowing CS had more trials been conducted. There are no data directly relevant to this proposition but, as was noted in Experiment 2, Schachtman et al. (1983) found that attenuation of Kamin blocking produced by a pretest "reminder treatment" (presentation of the blocked CS in a novel context) was positively related to the number of compound conditioning trials. Schachtman et al. speculated that the blocked CS-US association continues to be strengthened on compound trials, and although such strengthening is not directly manifest in responding, this additional "latent associative strength" makes the association more prone to recovery. The same reasoning may apply to extinction of the overshadowing CS; greater compound conditioning may enhance the effectiveness of extinction of the overshadowing CS.

A second difference between the present experiments and those of Matzel et al. (1985; Matzel et al., 1987) and Kaufman and Bolles (1981) is the conditioning preparation. To date, attenuation of overshadowing following extinction of the overshadowing CS has been observed only in fear conditioning with such stimuli as tones and lights. Although it is not clear why attenuation of overshadowing via extinction of the overshadowing CS should be specific to fear conditioning when the basic overshadowing deficit is obtainable in both conditioned fear and conditioned taste aversion (and other preparations as well), this is a possibility that cannot be categorically rejected. It is possible that conditioned taste aversions are less readily altered by postconditioning modification than are other types of associations. There is, however, much evidence to argue against this claim. Previously published studies have yielded unmasking of latent flavor aversions by treatments such as reinstatement (Schachtman, Brown, \& Miller, 1985; Schachtman, Gustavson, Chelonis, \& Bourne, in press), as well as context manipulations (Puente, Cannon, Best, \& Carrell, 1988). Additionally, postconditioning attenuation of conditioned inhibition with flavors has also been obtained when the physical context that was used for training the inhibitor was extinguished after inhibitory training (Best, Dunn, Batson, Meachum, \& Nash, 1985). The latter finding shows that flavors are sensitive to posttraining extinction of stimuli (i.e., contextual cues in the Best et al., 1985, study) that were present along with that target flavor during original conditioning. It is not clear if the discrepancy between the present results and those of Best et al. is due to the use of contextual cues versus punctate cues or to conditioned inhibitory training versus conditioned excitatory training.

In summary, the present results may not refute those of Kaufman and Bolles (1981) and Matzel et al. (1985; Matzel et al., 1987), but rather they suggest limits to their generality. It is clear from the preceding discussion that there are several dimensions along which subsequent research should proceed in order to understand the conditions under which one may expect attenuation of overshadowing following extinction of the overshadowing CS.

\section{REFERENCES}

Best, M. R., Dunn, D. P., Batson, J. D., Meachum, C. L., * Nash, S. M. (1985). Extinguishing conditioned inhibition in flavor-aversion learning: Effects of repeated testing and extinction of the excitatory element. Quarterly Joumal of Experimental Psychology, 37B, 359-378.

Gordon, W. C., Smith, G. J., \& KaTz, D. S. (1979). Dual effects of response blocking following avoidance learning. Behavior Research \& Therapy, 17, 479-487.

JAMES, J. H., \& WAGNER, A. R. (1980). One-trial overshadowing: Evidence of distributive processing. Journal of Experimental Psychology: Animal Behavior Processes, 6, 188-205.

KAmiN, L. J. (1969). Predictability, surprise and attention. In B. Campbell \& R. Church (Eds.), Punishment and aversive behavior (pp. 279296). New York: Appleton-Century-Crofts.

Kasprow, W. J., Cacheiro, H., Balaz, M. A., Miller, R. R. (1982). Recovery of associations to an overshadowed stimulus. Leaming \& Motivation, 13, 155-166.

Kasprow, W. J., Schachtman, T. R., \&iller, R. R. (1987). The comparator hypothesis of conditioned response generation: Manifest conditioned excitation and inhibition as a function of relative excitatory strengths of CS and conditioning context at the time of testing. Journal of Experimental Psychology: Animal Behavior Processes, 13, 395-406.

Kaufman, M. A., \& Bolles, R. C. (1981). A nonassociative aspect of overshadowing. Bulletin of the Psychonomic Society, 18, 318-320.

Kaye, H., Gambini, B., \& Mackintosh, N. J. (1988). A dissociation between one-trial overshadowing and the effect of a distractor on habituation. Quarterly Journal of Experimental Psychology, 40B, 31-47. MACKINTOSH, N. J. (1971). Analysis of overshadowing and blocking. Quarterly Journal of Experimental Psychology, 23, 118-125. 
Mackintosh, N. J. (1976). Overshadowing and stimulus intensity. $A n$ imal Leaming \& Behavior, 4, 186-192.

Mackintosh, N. J., \& ReESE, B. (1979). One trial overshadowing. Quarterly Joumal of Experimental Psychology, 31, 519-526.

Matzel, L. D., Schachtman, T. R., Miller, R. R. (1985). Recovery of an overshadowed association achieved by extinction of the overshadowing stimulus. Learning \& Motivation, 16, 398-412.

Matzel, L. D., Shuster, K., \& Miller, R. R. (1987). Covariation in conditioned response strength between stimuli trained in compound. Animal Learning \& Behavior, 15, 439-447.

Miller, R. R., \& Schachtman, T. R. (1985). Conditioning context as an associative baseline: Implications for response generation and conditioned inhibition. In R. R. Miller \& N. E. Spear (Eds.), Information processing in animals: Conditioned inhibition (pp. 51-88). Hillsdale, NJ: Erlbaum.

Pavlov, I. P. (1927). Conditioned reflexes. Oxford: Oxford University Press.

Puente, G. P., Cannon, D. S., Best, M. R., \& Carrell, L. E. (1988). Occasion setting of fluid ingestion by contextual cues. Learning \& Motivation, 19, 239-253.

RESCORLA, R. A. (1980). Simultaneous and successive associations in sensory preconditioning. Journal of Experimental Psychology: Animal Behavior Processes, 6, 207-216.

Rescorla, R. A. (1982). Simultaneous second-order conditioning produces S-S learning in conditioned suppression. Joumal of Experimental Psychology: Animal Behavior Processes, 8, 23-32.

Revusky, S., PARKer, L. A., \& CoOMBes, S. (1977). Flavor aversion learning: Extinction of the aversion to an interfering flavor after conditioning does not affect the aversion to the refenence flavor. Behavioral Biology, 19, 503-508.

Schachtman, T. R., Brown, A. M., Gordon, E., Catterson, D. \& MiLLER, R. R. (1987). Mechanisms underlying retarded emergence of conditioned responding following inhibitory training: Evidence for the comparator hypothesis. Journal of Experimental Psychology: Animal Behavior Processes, 13, 310-322.

Schachtman, T. R., Brown, A. M., \& Miller, R. R. (1985). Reinstatement-induced recovery of a taste- $\mathrm{LiCl}$ association following extinction. Animal Learning \& Behavior, 13, 223-227.

Schachtman, T. R., Gee, J. L., Kasprow, W. J., Miller, R. R. (1983). Reminder-induced recovery from blocking as a function of number of compound trials. Learning \& Motivation, 14, 154-164. Schachtman, T. R., Gustavson, K. K., Chelonis, J. J., \& Bourne, M. J. (in press). Effects of US reinstatement on the potential of an extinguished CS to attenuate manifest learning about another CS. Learning \& Motivation.

SPEAR, N. E. (1978). The processing of memories: Forgetting and retention. Hillsdale, NJ: Erlbaum.

Speers, M. A., Gillan, D. J., \& Rescorla, R. A. (1980). Withincompound associations in a variety of conditioning procedures. Learning \& Motivation, 11, 135-149.

(Manuscript received February 6, 1991; revision accepted for publication January 23, 1992.) 